\title{
Tobacco smoking and intestinal metaplasia: Systematic review and meta-analysis
}

\author{
Samantha Morais ${ }^{a}$, Sandra Rodrigues ${ }^{a}$, Liliana Amorim ${ }^{a}$, \\ Bárbara Peleteiro ${ }^{\mathrm{a}, \mathrm{b}}$, Nuno Lunet ${ }^{\mathrm{a}, \mathrm{b}, *}$ \\ a EPIUnit - Institute of Public Health, University of Porto, Porto, Portugal \\ ${ }^{\mathrm{b}}$ Department of Clinical Epidemiology, Predictive Medicine and Public Health of the University of Porto Medical School, Porto, Portugal
}

\section{A R T I C L E I N F O}

\section{Article history:}

Received 27 May 2014

Accepted 2 August 2014

Available online 5 September 2014

\section{Keywords:}

Meta-analysis

Precancerous conditions

Smoking

Stomach neoplasms

\begin{abstract}
A B S T R A C T
Background: The evaluation of specific risk factors for early endpoints in the gastric carcinogenesis pathway may further contribute to the understanding of gastric cancer aetiology.

Aims: To quantify the relation between smoking and intestinal metaplasia through systematic review and meta-analysis.

Methods: Articles providing data on the association between smoking and intestinal metaplasia were identified in PubMed ${ }^{\circledR}$, Scopus ${ }^{\circledR}$ and Web of Science ${ }^{\mathrm{TM}}$, searched until April 2014, and through backward citation tracking. Summary odds ratio estimates and $95 \%$ confidence intervals were computed using the DerSimonian and Laird method. Heterogeneity was quantitatively assessed using the $I^{2}$ statistic.

Results: A total of 32 articles were included in this systematic review and 19 provided data for meta-analysis. Smoking was defined as ever vs. never (crude estimates, six studies, summary odds ratio $=1.54,95 \%$ confidence interval: $1.12-2.12, I^{2}=67.4 \%$; adjusted estimates, seven studies, summary odds ratio $=1.26,95 \%$ confidence interval: $0.98-1.61, I^{2}=65.0 \%$ ) and current vs. non-smokers (crude estimates, seven studies, summary odds ratio $=1.27,95 \%$ confidence interval: $0.88-1.84, I^{2}=73.4 \%$; adjusted estimates, two studies, summary odds ratio $1.49,95 \%$ confidence interval: $0.99-2.25, I^{2}=0.0 \%$ ).

Conclusion: The weak and non-statistically significant association found through meta-analysis of the available evidence does not confirm smoking as an independent risk factor for intestinal metaplasia.
\end{abstract}

(c) 2014 Editrice Gastroenterologica Italiana S.r.l. Published by Elsevier Ltd. All rights reserved.

\section{Introduction}

Gastric cancer is the fifth most common malignancy in the world and the third leading cause of cancer mortality worldwide [1]. Incidence and mortality rates have been diminishing for several decades [2,3], mostly due to the decrease in the frequency of cancers of the "intestinal" histological type [4,5], which account for approximately up to three-quarters of the total [4,6-9]. However, recent trends show that in some countries the declines are becoming less marked [3].

It is widely accepted that intestinal type gastric carcinomas are preceded by atrophic gastritis, intestinal metaplasia (IM), and dysplasia, following a set of sequential steps, known as Correa's cascade

\footnotetext{
* Corresponding author at: Departamento de Epidemiologia Clínica, Medicina Preditiva e Saúde Pública, Faculdade de Medicina da Universidade do Porto, Al. Prof. Hernâni Monteiro, 4200-319 Porto, Portugal. Tel.: +351 225513652.

E-mail address: nlunet@med.up.pt (N. Lunet).
}

[10]. Although Helicobacter pylori infection plays an essential role in this process, other environmental exposures are needed for the progression towards cancer [11]. The evaluation of specific risk factors for early endpoints in the gastric carcinogenesis pathway may further contribute to the understanding of gastric cancer aetiology.

Gastric cancer is now considered a tobacco-related cancer $[12,13]$; current smokers were estimated to have a higher risk of gastric cancer when compared to never smokers (summary relative risk estimates: 1.62 in men and 1.20 in women) [14,15]. The associations are lower when comparing former and never smokers (summary relative risk estimates: 1.34 in men and 1.16 in women) suggesting smoking cessation leads to a reduction in risk [16]. The relation between smoking and precancerous lesions, especially IM, has been extensively studied [17]; however, to our knowledge, no meta-analyses of studies quantifying this association are available.

We aimed to quantify the relation between tobacco smoking and IM through systematic review and meta-analysis of the published epidemiological evidence. 


\section{Materials and methods}

A study protocol was predefined by the authors and followed throughout the review.

\subsection{Search strategy}

PubMed $^{\circledR}$, Scopus $^{\circledR}$ and Web of Science ${ }^{\mathrm{TM}}$ were searched, from inception to April 2014, to identify published articles evaluating the relationship between tobacco smoking and IM, with no language restrictions; the search expressions are provided in the PRISMA systematic review flowchart (Fig. 1). The list of bibliographic references of the original reports considered eligible for the systematic review and review articles on these topics were also screened.

\subsection{Selection of the studies}

The list of references was independently screened by three reviewers (SM, SR and LA), in three consecutive steps, applying predefined criteria. In the first step, studies were excluded considering only information presented in the title and abstract. In the second step, full texts of articles not previously excluded were assessed to determine their eligibility for the systematic review. In the last step, full texts were re-evaluated to determine eligibility for metaanalysis.

Published articles were included when all of the following criteria were met: (1) original reports of case-control or cross-sectional studies, including baseline evaluations of randomized clinical trials or cohort studies; (2) articles addressing the association between tobacco smoking and the occurrence of IM in human adults; (3) exposure defined as smoking cigarettes, pipes, bidis or cigars; and (4) outcome defined as intestinal metaplasia of the stomach, excluding the cardia, as this is a more heterogeneous condition that may follow the aetiology of oesophageal more closely than that of gastric cancer [18-20]. Among reports with overlapping samples, we selected those providing data regarding the largest number of cases or presenting more detailed information regarding tobacco exposure.

The decisions taken independently by the reviewers in each step were compared and discrepancies were resolved by consensus, or involving a fourth researcher (BP or NL).

\subsection{Data extraction and meta-analysis}

We extracted data on the following items: publication year; country where the sample was assembled; selection of the participants and sample size; number of biopsy fragments and criteria used for the diagnosis of IM; odds ratio (OR) estimates and corresponding $95 \%$ confidence intervals $(95 \% \mathrm{CI}$ ), or the necessary information to compute them, for the association between smoking and IM; control for potential confounding factors.

When a study provided OR estimates adjusted for a different number of potential confounders, the one adjusted for the largest number of variables was selected. For studies providing adjusted estimates only for the relation between exposures other than smoking and IM, crude estimates for the association between smoking and IM were computed if sufficient data was available. Lastly, if only crude estimates or the necessary information to compute them were available, these were extracted.

When data regarding IM in different stomach locations were presented separately, the measures referring to antrum were selected for meta-analyses, as this better reflects the more frequent location of adenocarcinomas, specially of the intestinal type [20-23].
Data extraction was performed independently by two researchers (SM and SR) and disagreements were resolved by consensus, or involving a third researcher (BP or NL).

We conducted meta-analyses for the association between smoking (ever vs. never and current vs. non-smokers) and IM. The DerSimonian and Laird method was used to compute summary OR estimates, and respective 95\% CI. Heterogeneity was quantified using the $I^{2}$ statistic [24]. Visual inspection of the funnel plots and the Egger's regression asymmetry test were used for assessment of publication bias [25]. Sensitivity analyses were carried out taking different inclusion criteria into account, as described in the footnotes of the forest plots used to summarize the results.

The statistical analysis was performed with STATA ${ }^{\circledR}$, version 11 (STATA Corp., College Station, TX, USA).

\section{Results}

\subsection{Systematic review}

Thirty-two articles were included in the systematic review (Supplementary Tables S1 and S2). Fifteen studies were conducted in Asia [26-40] (five from Japan, four from China, three from Korea, two from Iran and one from Taiwan), eight in Europe [41-48] (a multicentre study and one each from England, Finland, Italy, Netherlands, Poland, Portugal and Spain), four in North America [49-52] (participants were Asian/Hawaiian in two of them), three in South America [53-55] (Venezuela, Peru and El Salvador) and one each in Oceania [56] (New Zealand) and in Africa [57] (Mozambique).

Seventeen studies [27,28,30-33,40,41,43,44,46-52,56,57] recruited only patients referred due to gastrointestinal complaints. Twelve study populations [26,29,35-37,39,45,53-55] included volunteers from community screening programmes. Two studies $[38,42]$ included participants referred due to gastrointestinal complaints as well as volunteers, and one study [34] recruited first-degree relatives of gastric cancer patients.

The number of biopsies performed for histological diagnosis ranged between two and 14 (Supplementary Tables S1 and S2); however, three articles [36,49,51] did not provide information on the number of biopsies. Only 15 studies specified the classification system used to assess IM; from these, 13 studies $[11,27,30-32,34,35,37,38,43,44,47,48]$ used the Updated Sydney System.

\subsection{Meta-analyses}

A total of 19 articles [28-30,32-38,42,48,50-56] provided quantitative information on the relation between tobacco smoking and IM, most of them following a cross-sectional evaluation of the participants ( 17 cross-sectional, from which six were a baseline evaluation of a cohort and one a baseline evaluation of a randomized controlled trial) and five were case-control studies (Supplementary Table S1).

\subsubsection{Ever vs. never smokers}

A total of 13 studies [28,29,32,33,35-37,42,48,50,51,53,55], evaluating 3410 IM patients and 8630 controls, classified smoking exposure as ever vs. never (Fig. 2). The combined OR estimate for the association between ever smoking and IM was 1.54 (95\% CI: $1.12-2.12, I^{2}=67.4 \%$ ) for crude estimates, and 1.26 (95\% CI: $\left.0.98-1.61, I^{2}=65.0 \%\right)$ when considering only the seven studies providing adjusted OR estimates. The results remained essentially unchanged when sensitivity analyses were conducted (Fig. 2).

Visual inspection of the funnel plot for ever vs. never smoking (Fig. 4) suggested an underrepresentation of small studies with 


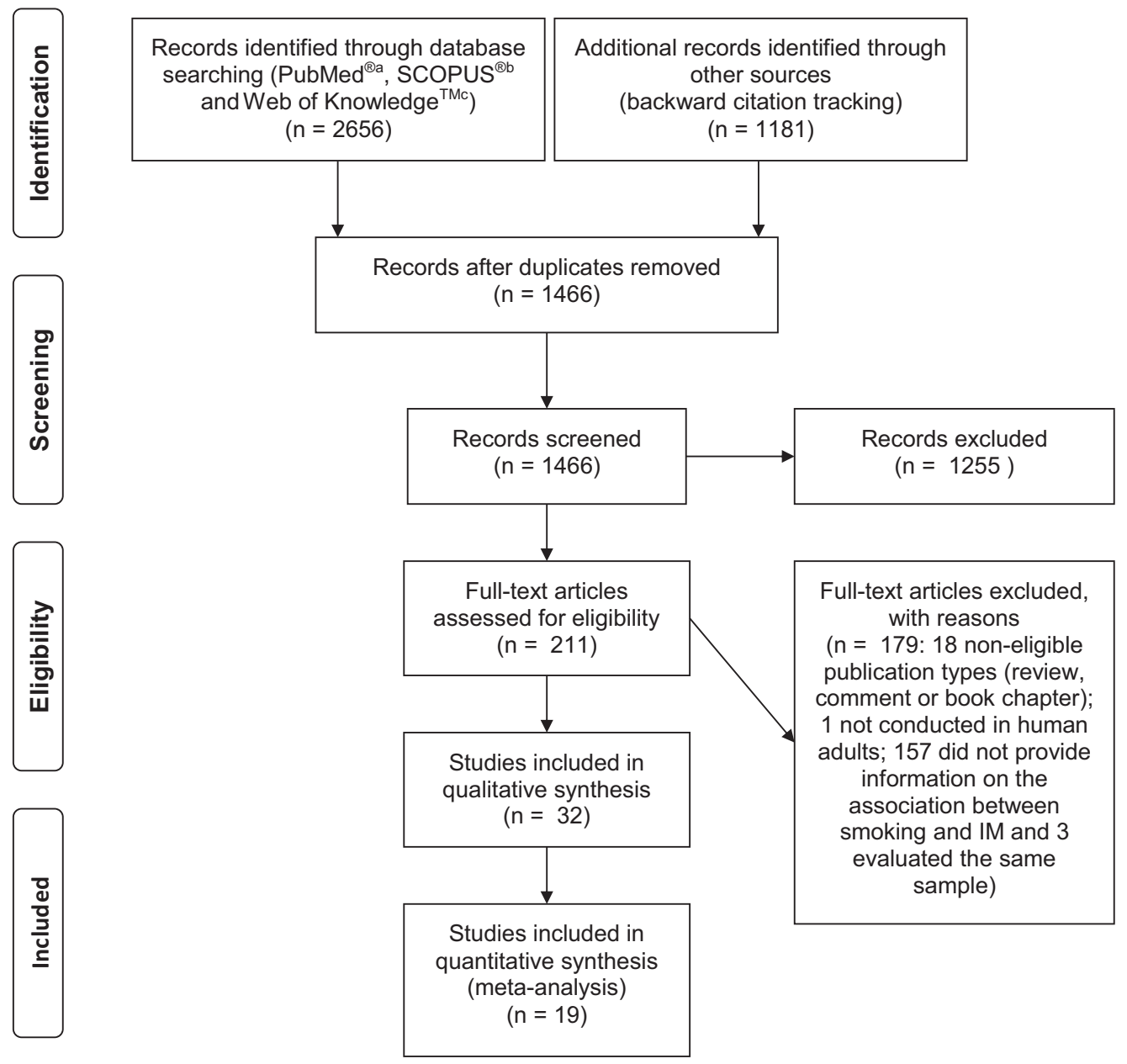

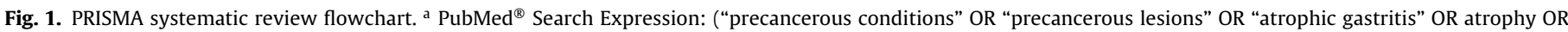

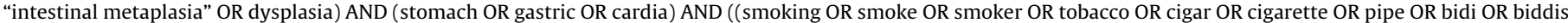

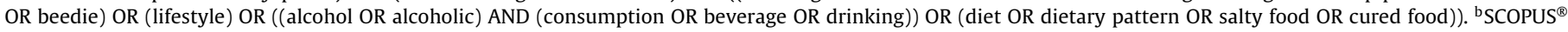

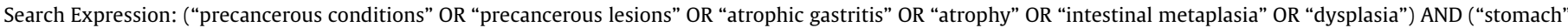

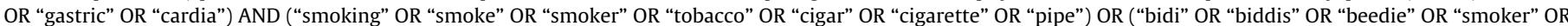

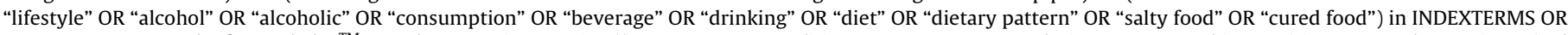

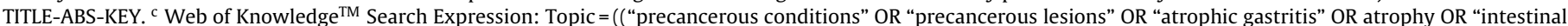

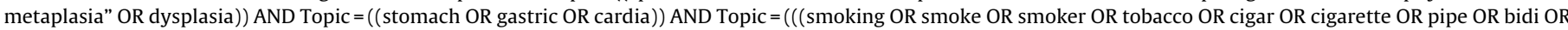

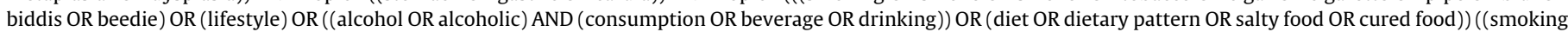

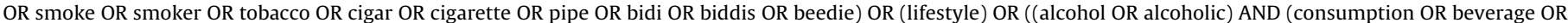
drinking)) OR (diet OR dietary pattern OR salty food OR cured food))).

negative associations, although the Egger's regression asymmetry test ( $p=0.133$ ) showed no statistically significant bias.

\subsubsection{Current vs. non-smokers}

Nine studies $[30,34,38,42,51,52,54-56]$ included in this metaanalysis, evaluating 1050 IM patients and 4280 controls, compared current and non-smokers (Fig. 3). All studies, except one [51], showed a positive association between exposure and outcome.

The combined OR estimate for the association between current smoking and IM was 1.27 (95\% CI: $0.88-1.84, I^{2}=73.4 \%$ ) for crude estimates and 1.49 (95\% CI: 0.99-2.25, $\left.I^{2}=0.0 \%\right)$ when considering only the two studies (conducted in subjects referred due to gastrointestinal complaints) which provided adjusted estimates (Fig. 3).

Visual inspection of the funnel plot for current vs. non-smokers (Fig. 4) suggested an underrepresentation of small studies with stronger positive associations, in accordance with the Egger's regression asymmetry test $(p=0.046)$.

\subsection{Studies not considered for meta-analysis}

A total of 13 articles [26,27,31,39-41,43-47,49,57] included in the systematic review were not included in the meta-analysis as they did not provide enough information to compute quantitative estimates regarding the exposure to tobacco, compared exposure or outcome categories not directly comparable with those presented in most of the other reports, or evaluated only $H$. pylori-infected subjects (Supplementary Table S2).

One study [26] showed the mean metaplasia score for nonsmokers and smokers (3.4 and 2.6, respectively, $p$-value $=0.10$ ) and another [41] did not provide detailed information concerning tobacco exposure as it compared the number of cigarettes smoked and found that smoking 10 or more cigarettes a day was associated with a definite increase in IM $(p<0.002)$.

Other articles [27,31,39,40,43,44,49,57] included participants which all had IM with different extents and severities. For example, Jedrychowski et al. [44] compared participants with moderate or severe IM vs. those with nil or mild IM and found a significant association for ever vs. never smokers ( $\mathrm{OR}=1.42,95 \% \mathrm{CI}$ : $1.10-1.84)$. 


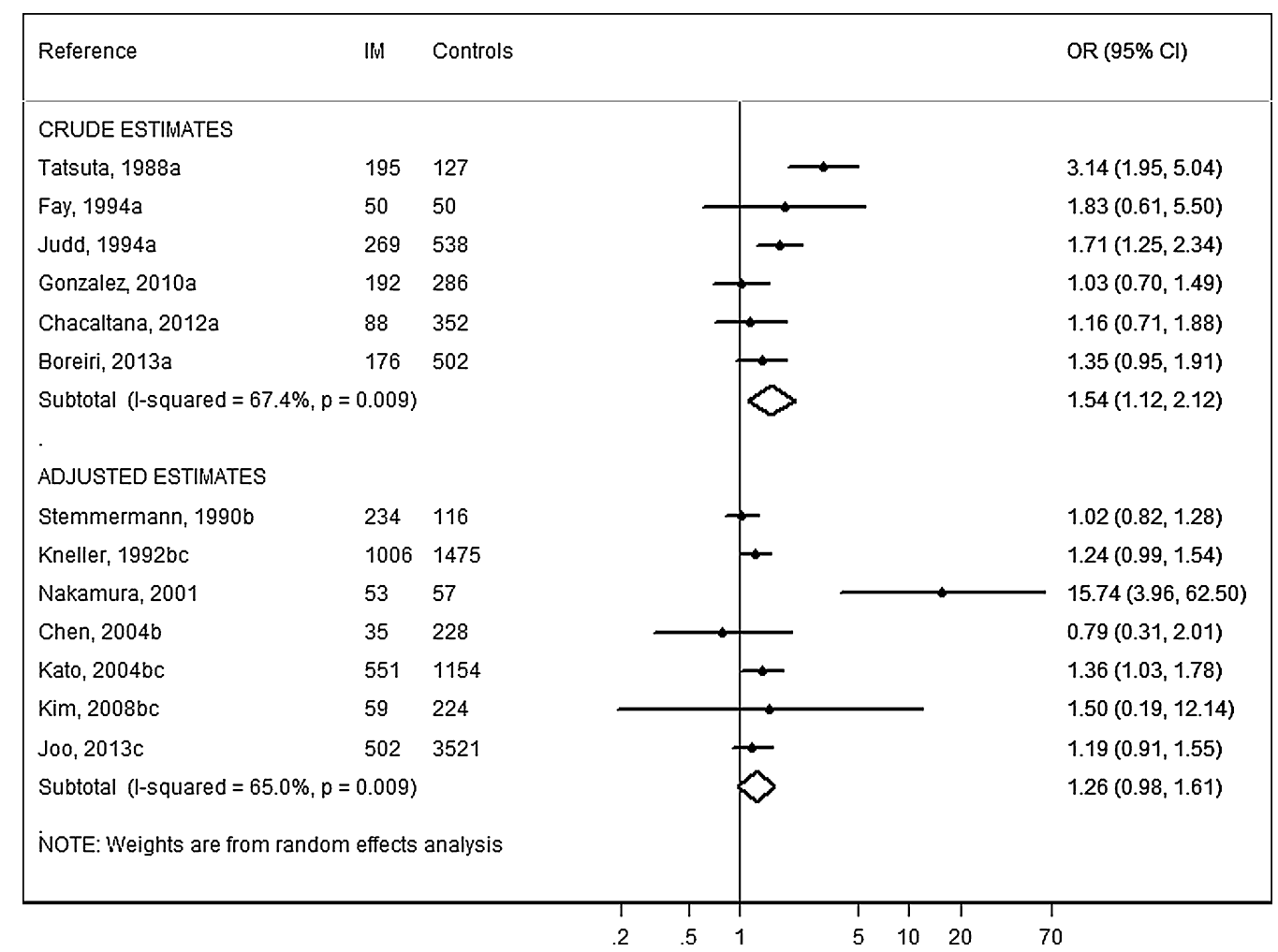

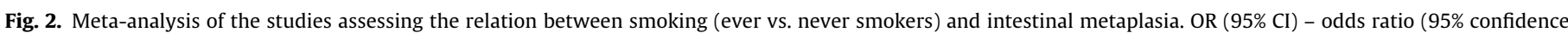

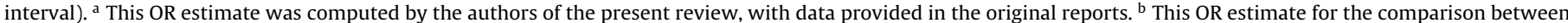

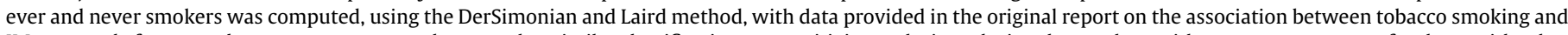

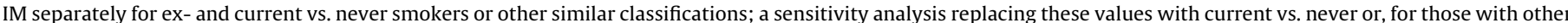

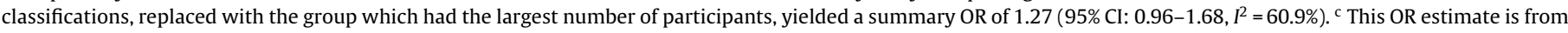

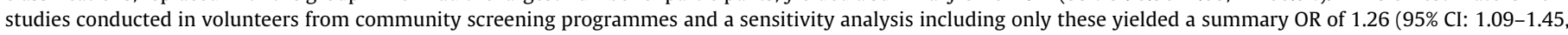
$I^{2}=0.0 \%$.

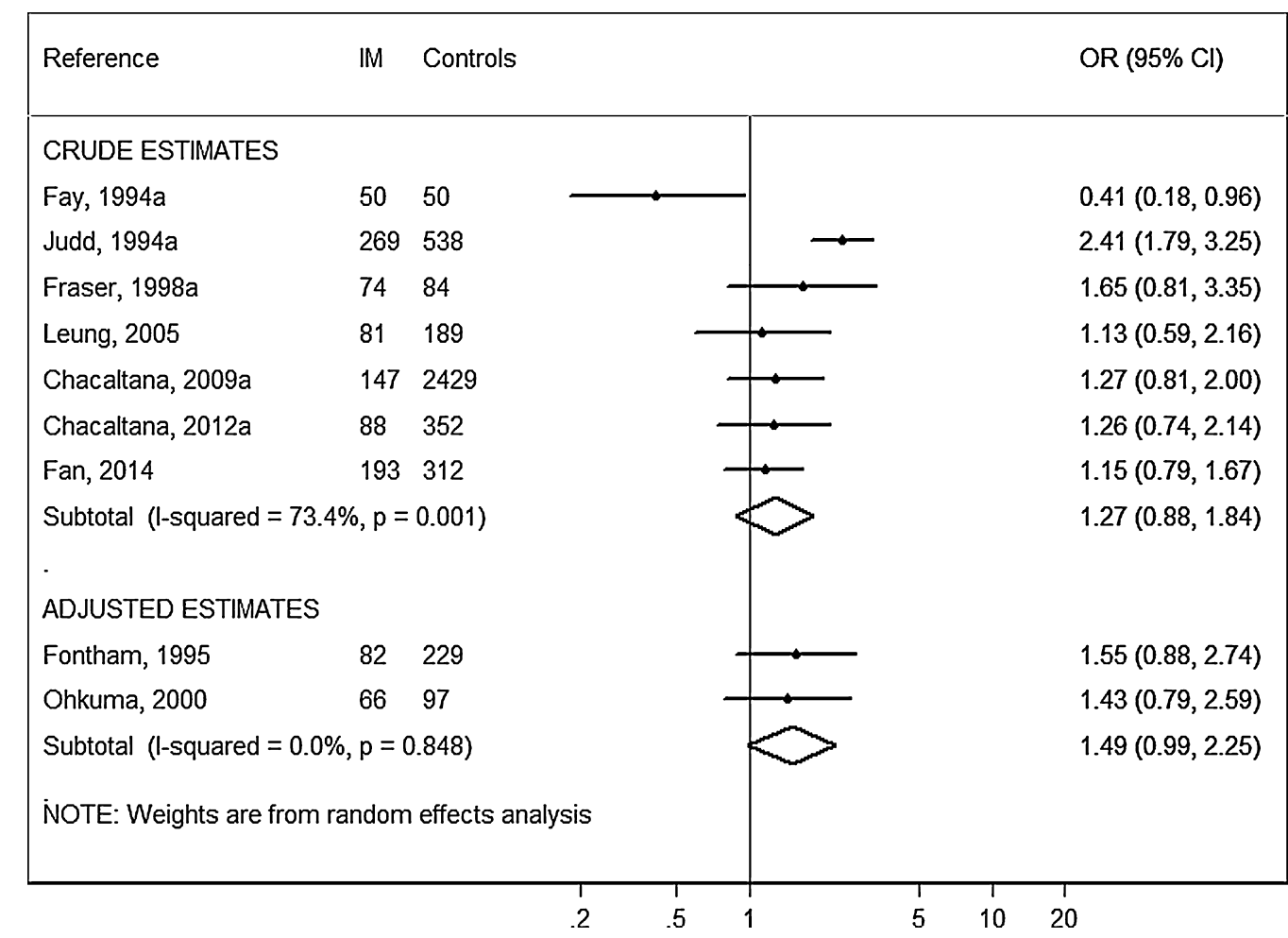

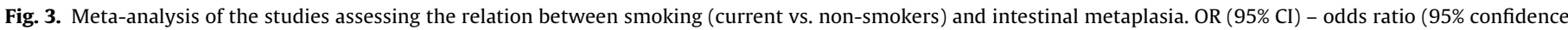
interval). ${ }^{\text {a }}$ This OR estimate was computed by the authors of the present review, with data provided in the original reports. 
(a)

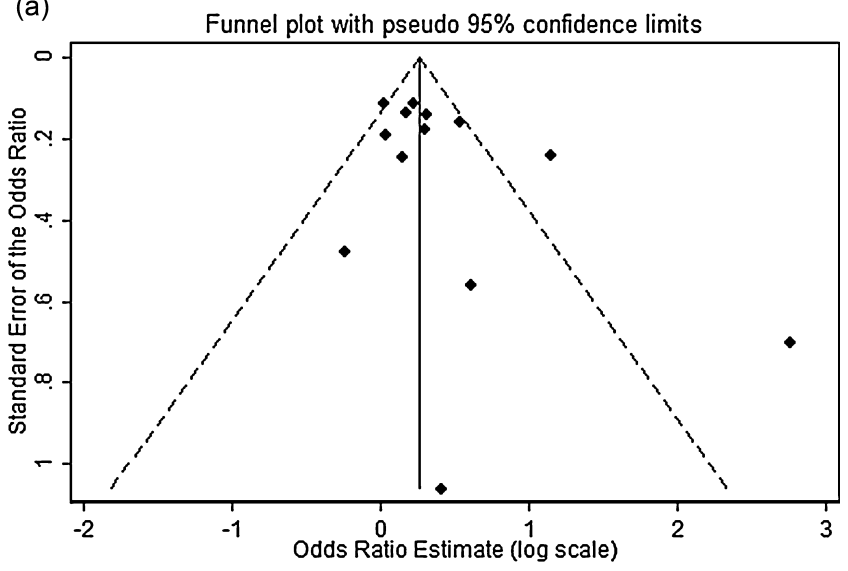

Current vs. Non-smoker

(b) Funnel plot with pseudo $95 \%$ confidence limits

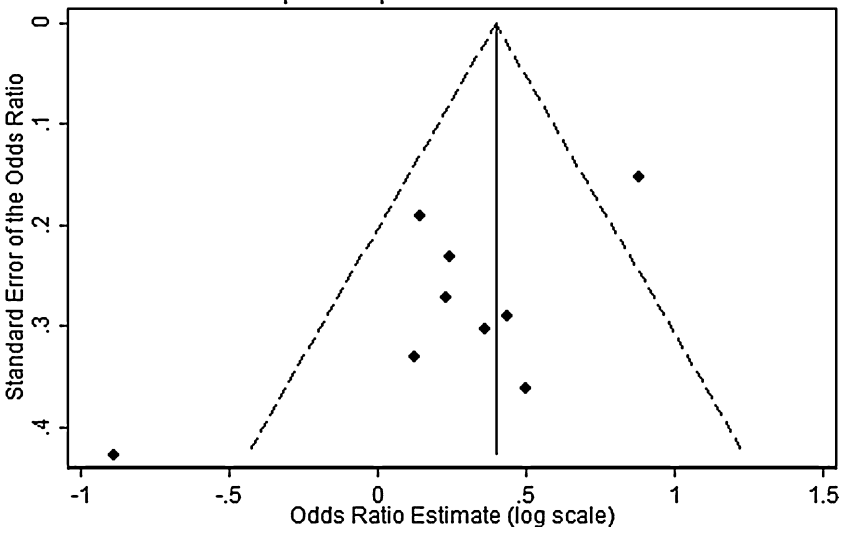

Fig. 4. Funnel plots of the studies assessing the relation between smoking (ever vs. never and current vs. non-smokers) and intestinal metaplasia.

Abadir et al. [49] and Chooi et al. [27] compared patients according to the progression of the pathology and also found a clear positive association between tobacco smoking and IM progression.

Three studies [45-47] included only subjects infected with $H$. pylori. Koivisto et al. [47] showed virtually no differences between current and non-smokers ( $\mathrm{OR}=1.04,95 \% \mathrm{CI}$ : 0.58-1.88), whereas the remaining showed a positive association that increased with the amount smoked (Russo et al. [45], OR=1.79, 95\% CI: 0.95-3.31 for ex- vs. never smokers, $\mathrm{OR}=1.88,95 \% \mathrm{CI}$ : $0.91-3.89$ for smokers of $\leq 20$ cigarettes/day vs. never smokers and $\mathrm{OR}=4.75,95 \%$ CI: $1.33-16.99$ for smokers of $>20$ cigarettes/day vs. never smokers; Peleteiro et al. [46], OR=1.78, 95\% CI: 0.84-3.76 for ex- vs. never smokers and $\mathrm{OR}=3.19,95 \% \mathrm{CI}: 1.51-6.73$ for current vs. never smokers).

\section{Discussion}

To our knowledge, this is the first systematic review on the relationship between tobacco smoking and IM. The meta-analysis shows a weak and non-statistically significant positive association, with odds being $25-50 \%$ higher among smokers.

We conducted a comprehensive systematic review using more than one database and backward citation tracking. Although no evidence of publication bias was observed for the ever vs. never analysis, there was an underrepresentation of small studies with stronger positive associations in the current vs. non-smokers analysis. This reflects the fact that the association between smoking and IM is weak, and OR estimates are likely to be even closer to the null when ex-smokers are included in the reference category, since the risk of IM in this group is closer to current than non-smokers, and these individuals may have quit smoking because of associated gastric pathologies [6,58]. Furthermore, as these results are based on a large number of studies, it is unlikely that the inclusion of additional unpublished data would change our conclusions.

A high variability among studies was observed concerning the adjustment for possible confounders, populations evaluated and assessment of IM, which needs to be taken into account when interpreting the homogeneity of the results across studies, and the validity of the summary estimates.

For most of the studies, quantifying the association between smoking and IM was not the main objective, hence adjusted ORs were presented for exposures other than smoking and only the necessary information to compute crude ORs for smoking was available. Older people are known to have a higher risk of IM $[23,59]$, and are more likely to have been exposed to smoking throughout life. Although an age restriction to include participants older than 40 years old was used in a few of the studies, crude estimates are likely to be confounded. On the other hand, even though the studies providing adjusted measures of association took into account different sets of potential confounders, all accounted for the effect of age.

In addition to a higher prevalence of daily smoking being observed in men compared to women, the average number of cigarettes smoked per day by men is higher than for women, probably leading to a higher cumulative tobacco exposure in men [60-62]. Considering that all studies relied on a broad definition of exposure to smoking, reflecting different levels of consumption among the smokers, we would expect higher OR estimates in men compared to women, as observed for gastric cancer [16]; however, we were unable to conduct an analysis stratified by gender, which may have contributed to the moderately high heterogeneity observed. Most studies, including those in this systematic review, acknowledge the importance of taking into account the amount and duration of tobacco exposure, and highlight the need for models to quantify the effect of tobacco exposure over time on the gastric mucosa.

Another feature, which may have contributed to heterogeneity, is that the source population was mainly comprised of participants with gastric complaints. The majority of the studies used as controls groups with some change of the gastric mucosa, which may be associated with tobacco smoking [63,64].

The diversity in the number of biopsies and the method used to assess IM may have also contributed to variability in the prevalence of IM. Classification methods other than the Updated Sydney System were used and although some appear to be similar, it is possible that specific changes to the original system may compromise the comparison between studies. Of particular interest, is the article by Nam et al. [39], which used the Operative Link on Gastric Intestinal Metaplasia Assessment (OLGIM), a recent classification system, and provided estimates for high-risk stages of IM.

It has been widely accepted that smoking is an important behavioural risk factor for gastric cancer, despite the weak association observed $[16,65,66]$. Although only a few studies specifically evaluated this association according to histological type, the available evidence does not support significant differences according to the main subtypes [6,67-69]. Regarding the relation between smoking and precancerous lesions, most studies addressing chronic atrophic gastritis failed to clearly demonstrate an association $[35,36,52,53,70]$, and the current meta-analysis is inconclusive regarding a causal role of smoking in the occurrence of IM. Nevertheless, taken together these results are in accordance with the hypothesis of smoking acting mostly in late gastric carcinogenesis.

In conclusion, the present systematic review and meta-analysis does not confirm smoking as an independent risk factor for IM. Additional methodologically robust studies are needed to reduce 
heterogeneity and clarify the role of uncontrolled confounding in the weak and non-statistically significant association observed.

\section{Conflict of interest}

None declared.

\section{Acknowledgement}

This work was supported by "Fundação para a Ciência e a Tecnologia” (PTDC/SAUEPI/122460/2010 and SFRH/BPD/75918/2011).

\section{Appendix A. Supplementary data}

Supplementary material related to this article can be found, in the online version, at http://dx.doi.org/10.1016/j.dld.2014.08.034.

\section{References}

[1] GLOBOCAN 2012: Estimated cancer incidence, mortality and prevalence worldwide in 2012; 2012. Available at: http://globocan.iarc.fr/Pages/fact_sheets_cancer.aspx

[2] Peleteiro B, Severo M, La Vecchia C, et al. Model-based patterns in stomach cancer mortality worldwide. European Journal of Cancer Prevention http://dx.doi.org/10.1097/CEJ.0b013e328364f2b6 [E-pub ahead of print].

[3] Ferro A, Peleteiro B, Malvezzi M, et al. Worldwide trends in gastric cancer mortality (1980-2011), with predictions to 2015, and incidence by subtype. European Journal of Cancer 2014;50:1330-44

[4] Wu H, Rusiecki JA, Zhu K, et al. Stomach carcinoma incidence patterns in the United States by histologic type and anatomic site. Cancer Epidemiology, Biomarkers and Prevention 2009; 18:1945-52.

[5] Camargo MC, Anderson WF, King JB, et al. Divergent trends for gastric cancer incidence by anatomical subsite in US adults. Gut 2011;60:1644-9.

[6] Koizumi Y, Tsubono Y, Nakaya N, et al. Cigarette smoking and the risk of gastric cancer: a pooled analysis of two prospective studies in Japan. International Journal of Cancer 2004;112:1049-55.

[7] Santibanez M, Alguacil J, de la Hera MG, et al. Occupational exposures and risk of stomach cancer by histological type. Occupational and Environmental Medicine 2012;69:268-75.

[8] Ekstrom AM, Serafini M, Nyren O, et al. Dietary quercetin intake and risk of gastric cancer: results from a population-based study in Sweden. Annals of Oncology 2011;22:438-43.

[9] Peleteiro B, Lopes C, Figueiredo C, et al. Salt intake and gastric cancer risk according to Helicobacter pylori infection, smoking, tumour site and histological type. British Journal of Cancer 2011;104:198-207.

[10] Correa P, Haenszel W, Cuello C, et al. A model for gastric cancer epidemiology. Lancet 1975;2:58-60.

[11] Peleteiro B, La Vecchia C, Lunet N. The role of Helicobacter pylori infection in the web of gastric cancer causation. European Journal of Cancer Prevention 2012;21:118-25.

[12] IARC. Tobacco smoke and involuntary smoking. IARC Monographs on the Evaluation of Carcinogenic Risks to Humans 2004;83:1-1438.

[13] Gonzalez CA, Sala N, Capella G. Genetic susceptibility and gastric cancer risk. International Journal of Cancer 2002;100:249-60.

[14] Riboli E, Norat T. Epidemiologic evidence of the protective effect of fruit and vegetables on cancer risk. American Journal of Clinical Nutrition 2003;78:559s-69s

[15] Vincenzi B, Patti G, Galluzzo S, et al. Interleukin 1beta-511T gene (IL1beta) polymorphism is correlated with gastric cancer in the Caucasian population: results from a meta-analysis. Oncology Reports 2008;20:1213-20.

[16] Ladeiras-Lopes R, Pereira AK, Nogueira A, et al. Smoking and gastric cancer: systematic review and meta-analysis of cohort studies. Cancer Causes and Control 2008;19:689-701.

[17] Mesquita P, Raquel A, Nuno L, et al. Metaplasia-a transdifferentiation process that facilitates cancer development: the model of gastric intestinal metaplasia. Critical Reviews in Oncogenesis 2006;12:3-26.

[18] Marsman WA, Tytgat GN, ten Kate FJ, et al. Differences and similarities of adenocarcinomas of the esophagus and esophagogastric junction. Journal of Surgical Oncology 2005;92:160-8.

[19] Peleteiro B, Cavaleiro-Pinto M, Barros R, et al. Is cardia cancer aetiologically different from distal stomach cancer. European Journal of Cancer Prevention 2011;20:96-101.

[20] Correa P, Piazuelo MB, Wilson KT. Pathology of gastric intestinal metaplasia: clinical implications. American Journal of Gastroenterology 2010;105:493-8.

[21] Dinis-Ribeiro M, Areia M, de Vries AC, et al. Management of precancerous conditions and lesions in the stomach (MAPS): guideline from the European Society of Gastrointestinal Endoscopy (ESGE), European Helicobacter Study Group (EHSG), European Society of Pathology (ESP), and the Sociedade Portuguesa de Endoscopia Digestiva (SPED). Virchows Archiv 2012;460:19-46.

[22] de Vries AC, Haringsma J, de Vries RA, et al. Biopsy strategies for endoscopic surveillance of pre-malignant gastric lesions. Helicobacter 2010;15:259-64.
[23] Zullo A, Hassan C, Romiti A, et al. Follow-up of intestinal metaplasia in the stomach: when, how and why. World Journal of Gastrointestinal Oncology 2012;4:30-6.

[24] Higgins JP, Thompson SG. Quantifying heterogeneity in a meta-analysis. Statistics in Medicine 2002;21:1539-58.

[25] Sterne JA, Gavaghan D, Egger M. Publication and related bias in meta-analysis: power of statistical tests and prevalence in the literature. Journal of Clinical Epidemiology 2000;53:1119-29.

[26] Nomura A, Yamakawa H, Ishidate T, et al. Intestinal metaplasia in Japan: association with diet. Journal of the National Cancer Institute 1982;68: $401-5$.

[27] Chooi EY, Chen HM, Miao Q et al. Chronic atrophic gastritis is a progressive disease: analysis of medical reports from Shanghai (1985-2009). Singapore Medical Journal 2012;53:318-24.

[28] Tatsuta M, Iishi H, Okuda S. Effect of cigarette smoking on extent of acid-secreting area and intestinal metaplasia in the stomach. Digestive Diseases and Sciences 1988;33:23-9.

[29] Kneller RW, You WC, Chang YS, et al. Cigarette smoking and other risk factors for progression of precancerous stomach lesions. Journal of the National Cancer Institute 1992;84:1261-6.

[30] Ohkuma K, Okada M, Murayama H, et al. Association of Helicobacter pylor infection with atrophic gastritis and intestinal metaplasia. Journal of Gastroenterology and Hepatology 2000;15:1105-12.

[31] Nakamura M, Haruma K, Kamada T, et al. Cigarette smoking promotes atrophic gastritis in Helicobacter pylori-positive subjects. Digestive Diseases and Sciences 2002;47:675-81.

[32] Nakamura M, Haruma K, Kamada T, et al. Duodenogastric reflux is associated with antral metaplastic gastritis. Gastrointestinal Endoscopy 2001;53:53-9.

[33] Chen SY, Liu TY, Shun CT, et al. Modification effects of GSTM1, GSTT1 and CYP2E1 polymorphisms on associations between raw salted food and incomplete intestinal metaplasia in a high-risk area of stomach cancer. Internationa Journal of Cancer 2004;108:606-12.

[34] Leung WK, Ng EK, Chan WY, et al. Risk factors associated with the development of intestinal metaplasia in first-degree relatives of gastric cancer patients. Cancer Epidemiology, Biomarkers and Prevention 2005;14:2982-6.

[35] Kim N, Park YS, Cho SI, et al. Prevalence and risk factors of atrophic gastritis and intestinal metaplasia in a Korean population without significant gastroduodenal disease. Helicobacter 2008;13:245-55.

[36] Joo YE, Park HK, Myung DS, et al. Prevalence and risk factors of atrophic gastritis and intestinal metaplasia: a nationwide multicenter prospective study in Korea. Gut and Liver 2013;7:303-10.

[37] Boreiri M, Samadi F, Etemadi A, et al. Gastric cancer mortality in a high incidence area: long-term follow-up of Helicobacter pylori-related precancerous lesions in the general population. Archives of Iranian Medicine 2013;16: 343-7.

[38] Fan YF, Wu YM, Liu H, et al. TLR4 polymorphisms associated with developing gastric pre-cancer lesions in a Chinese Han population. Human Immunology 2014;75:176-81

[39] Nam JH, Choi IJ, Kook MC, et al. OLGA and OLGIM stage distribution according to age and Helicobacter pylori status in the Korean population. Helicobacter $2014 ; 19: 81-9$

[40] Mansour-Ghanaei F, Joukar F, Soati F, et al. Outcome of intestinal metaplasia in gastric biopsy of patients with dyspepsia in Guilan Province, North Iran. Asian Pacific Journal of Cancer Prevention 2013;14:3549-54.

[41] Shousha S, Barrison IG, El-Sayeed W, et al. A study of incidence and relationship of intestinal metaplasia of gastric antrum and gastric metaplasia of duodenum in patients with nonulcer dyspepsia. Digestive Diseases and Sciences 1984;29:311-6

[42] Judd PA. The ECP-EURONUT intestinal metaplasia study-lifestyle and dietary data. European Journal of Cancer Prevention 1994:3:81-8.

[43] de Vries AC, Haringsma J, de Vries RA, et al. The use of clinical, histologic, and serologic parameters to predict the intragastric extent of intestinal metaplasia: a recommendation for routine practice. Gastrointestinal Endoscopy 2009:70:18-25

[44] Jedrychowski W, Popiela T, Drews M, et al. Effect of Helicobacter pylori infection, smoking and dietary habits on the occurrence of antrum intestinal metaplasia. Clinico-epidemiological study in Poland. Polish Journal of Pathology 1999;50:289-95.

[45] Russo A, Maconi G, Spinelli P, et al. Effect of lifestyle, smoking, and diet on development of intestinal metaplasia in H. pylori-positive subjects. American Journal of Gastroenterology 2001;96:1402-8.

[46] Peleteiro B, Lunet N, Figueiredo C, et al. Smoking, Helicobacter pylori virulence, and type of intestinal metaplasia in Portuguese males. Cancer Epidemiology, Biomarkers and Prevention 2007;16:322-6.

[47] Koivisto TT, Voutilainen ME, Farkkila MA. Effect of smoking on gastric histology in Helicobacter pylori-positive gastritis. Scandinavian Journal of Gastroenterology 2008;43:1177-83.

[48] Gonzalez CA, Pardo ML, Liso JM, et al. Gastric cancer occurrence in preneoplastic lesions: a long-term follow-up in a high-risk area in Spain. International Journal of Cancer 2010;127:2654-60.

[49] Abadir A, Streutker C, Brezden-Masley C, et al. Intestinal metaplasia and the risk of gastric cancer in an immigrant Asian population. Clinical Medicine Insights: Gastroenterology 2012;5:43-50

[50] Stemmermann GN, Nomura AM, Chyou PH, et al. Impact of diet and smoking on risk of developing intestinal metaplasia of the stomach. Digestive Diseases and Sciences 1990;35:433-8. 
[51] Fay M, Fennerty MB, Emerson J, et al. Dietary habits and the risk of stomach cancer: a comparison study of patients with and without intestinal metaplasia. Gastroenterology Nursing 1994;16:158-62.

[52] Fontham ET, Ruiz B, Perez A, et al. Determinants of Helicobacter pylori infection and chronic gastritis. American Journal of Gastroenterology 1995;90:1094-101.

[53] Kato I, Vivas J, Plummer M, et al. Environmental factors in Helicobacter pylori-related gastric precancerous lesions in Venezuela. Cancer Epidemiology, Biomarkers and Prevention 2004;13:468-76.

[54] Chacaltana A, Rodriguez C, Urday C, et al. Preneoplastic gastric lesions and Helicobacter pylori in endoscopic detection and early diagnosis of gastric cancer in a population of a medium and high socio-economic level. Revista de Gastroenterologia del Peru 2009;29: 218-25.

[55] Chacaltana Mendoza A, Soriano Alvarez C, Frisancho Velarde O. Associated risk factors in patients with gastric intestinal metaplasia with mild gastroduodenal disease. Is it always related to Helicobacter pylori infection? Revista de Gastroenterologia del Peru 2012;32:50-7.

[56] Fraser AG, Peng SL, Jass JR. Intestinal metaplasia subtypes and Helicobacter pylori infection: a comparison of ethnic groups in New Zealand. Journal of Gastroenterology and Hepatology 1998;13:560-5.

[57] Peleteiro B, Barros R, Carrilho C, et al. Determinants of gastric CDX2 expression: a study in Mozambique. European Journal of Cancer Prevention 2012;21:532-40.

[58] Kim J, Cho YA, Choi IJ, et al. Effects of interleukin-10 polymorphisms, Helicobacter pylori infection, and smoking on the risk of noncardia gastric cancer. PLOS ONE 2012;7:e29643.

[59] Marques-Silva L, Areia M, Elvas L, et al. Prevalence of gastric precancerous conditions: a systematic review and meta-analysis. European Journal of Gastroenterology and Hepatology 2014;26:378-87.
[60] Ng M, Freeman MK, Fleming TD, et al. Smoking prevalence and cigarette consumption in 187 countries, 1980-2012. Journal of the American Medical Association 2014;311:183-92.

[61] Freedman ND, Leitzmann MF, Hollenbeck AR, et al. Cigarette smoking and subsequent risk of lung cancer in men and women: analysis of a prospective cohort study. Lancet Oncology 2008;9:649-56.

[62] Bain C, Feskanich D, Speizer FE, et al. Lung cancer rates in men and women with comparable histories of smoking. Journal of the National Cancer Institute 2004;96:826-34.

[63] Kurata JH, Nogawa AN. Meta-analysis of risk factors for peptic ulcer, Nonsteroidal antiinflammatory drugs, Helicobacter pylori, and smoking. Journal of Clinical Gastroenterology 1997;24:2-17.

[64] Mahadeva S, Goh KL. Epidemiology of functional dyspepsia: a global perspective. World Journal of Gastroenterology 2006;12:2661-6.

[65] Tredaniel J, Boffetta P, Buiatti E, et al. Tobacco smoking and gastric cancer: review and meta-analysis. International Journal of Cancer 1997;72:565-73.

[66] Nishino Y, Inoue M, Tsuji I, et al. Tobacco smoking and gastric cancer risk: an evaluation based on a systematic review of epidemiologic evidence among the Japanese population. Japanese Journal of Clinical Oncology 2006;36:800-7.

[67] Sasazuki S, Sasaki S, Tsugane S. Cigarette smoking, alcohol consumption and subsequent gastric cancer risk by subsite and histologic type. International Journal of Cancer 2002;101:560-6.

[68] Inoue M, Tajima K, Yamamura Y, et al. Influence of habitual smoking on gastric cancer by histologic subtype. International Journal of Cancer 1999;81:39-43.

[69] Ye W, Ekstrom AM, Hansson LE, et al. Tobacco, alcohol and the risk of gastric cancer by sub-site and histologic type. International Journal of Cancer 1999;83:223-9.

[70] Hishida A, Matsuo K, Goto Y, et al. Smoking behavior and risk of Helicobacter pylori infection, gastric atrophy and gastric cancer in Japanese. Asian Pacific Journal of Cancer Prevention 2010;11:669-73. 